\title{
Acessibilidade em transporte coletivo urbano na perspectiva dos motoristas e cobradores ${ }^{1}$
}

\author{
Alessandra Cavalcanti ${ }^{\mathrm{a}}$, Alysson Lourenço Alves ${ }^{\mathrm{b}}$, Ana Flávia Rodrigues Vieira ${ }^{\mathrm{c}}$, \\ Alberto Koston Aramakid, Ana Paula Santos Santana ${ }^{d}$

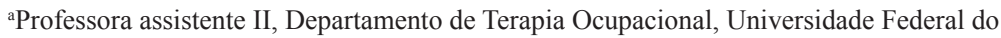 \\ Triângulo Mineiro - UFTM. Pesquisadora do Laboratório Integrado de Tecnologia Assistiva - LITA, \\ Universidade Federal do Triângulo Mineiro - UFTM, Uberaba, MG, Brasil \\ ${ }^{\text {b} T e r a p e u t a ~ o c u p a c i o n a l, ~ U n i v e r s i d a d e ~ F e d e r a l ~ d o ~ T r i a ̂ n g u l o ~ M i n e i r o ~-~ U F T M . ~}$ \\ Técnico pesquisador, Laboratório Integrado de Tecnologia Assistiva - LITA, \\ Universidade Federal do Triângulo Mineiro - UFTM, Uberaba, MG, Brasil \\ cAcadêmica bolsista de Iniciação Científica do curso de Terapia Ocupacional, Universidade Federal do Triângulo \\ Mineiro - UFTM, Estudante pesquisadora, Laboratório Integrado de Tecnologia Assistiva - LITA, \\ Universidade Federal do Triângulo Mineiro - UFTM, Uberaba, MG, Brasil \\ dAcadêmico do curso de Terapia Ocupacional, Universidade Federal do Triângulo Mineiro - UFTM, \\ Estudante pesquisador, Laboratório Integrado de Tecnologia Assistiva - LITA, \\ Universidade Federal do Triângulo Mineiro - UFTM, Uberaba, MG, Brasil
}

\begin{abstract}
Resumo: A mobilidade urbana acontece através dos deslocamentos a pé e do uso dos sistemas de transporte coletivo de passageiros. Um serviço de transporte que pode ser utilizado por todos visa a diminuição de barreiras que restringem a participação e limitam atividades, minimizando situações de desvantagem. Neste artigo, objetivou-se descrever a acessibilidade do transporte coletivo urbano no município de Uberaba, MG, na perspectiva do motorista condutor e do cobrador. Os dados foram coletados junto a motoristas e cobradores de uma das empresas de transporte coletivo da cidade, através de um formulário autoaplicável elaborado pelos pesquisadores e que continha três questões com respostas discursivas. Foram abordados 135 sujeitos para a pesquisa, sendo 35 excluídos por não estarem nos critérios de inclusão. A análise dos dados ocorreu pela análise de conteúdo temática, resultando no estabelecimento de três categorias. Os equipamentos foram relatados pela maioria dos sujeitos como inadequados, repercutindo numa acessibilidade ineficaz, e todos os sujeitos referiram serem capacitados para a utilização dos equipamentos de acessibilidade dos veículos
\end{abstract}

Palavras-chave: Equipamentos de Autoajuda, Condução de Veículo, Saúde da Pessoa com Deficiência ou Incapacidade.

\section{Accessibility in urban public transportation from the perspective of bus drivers and collectors}

\begin{abstract}
In cities, people commute mainly on foot or by public transportation. A bus system that can be used by everyone aims at reducing barriers that restrict participation and limit activities, minimizing situations of disadvantage. The objective of this study was to describe the accessibility of urban transportation in Uberaba, Minas Gerais state, from the perspective of bus drivers and collectors. Data were gathered from drivers and collectors of one of the transportation companies of the city through a self-administered form elaborated by the researchers, containing three questions with discursive answers. Data analysis occurred by thematic content analysis resulting in the establishment of three categories. One hundred thirty-five subjects were approached by the research, 35 were excluded for not belonging in the inclusion criteria. Most subjects refer to the equipment as inadequate, highlighting ineffective accessibility. All of the subjects surveyed consider themselves as being able to utilize the vehicles accessibility equipment.
\end{abstract}

Keywords: Self-help Devices, Automobile Driving, Health of the Disabled People.

Autor para correspondência: Alessandra Cavalcanti, Unidade Centro Educacional, Departamento de Terapia Ocupacional, Universidade Federal do Triângulo Mineiro, Av. Getúlio Guaritá, s/n, $3^{\circ}$ piso, sala 329, CEP 38025-440, Uberaba, MG, Brasil, e-mail: lita@ to.uftm.edu.br Recebido em 3/12/2012; Aceito em 17/1/2013. 


\section{Introdução}

A mobilidade cotidiana, fundamental, por exemplo, para as relaçôes sociais e de trabalho, acontece através dos deslocamentos a pé e do uso dos sistemas de transporte coletivo de passageiros. De acordo com o Código Brasileiro de Trânsito (BRASIL, 2008a, p. 315),

[...] nas áreas urbanas, os deslocamentos a pé e o uso do ônibus são as formas dominantes de deslocamento. Estima-se que no ano de 2001 estavam em circulação cerca de 115 mil ônibus, transportando 65 milhóes de passageiros por dia.

Sobre a perspectiva de mobilidade e de deslocamento pelos diferentes contextos e locais de um espaço urbano, a Constituição Federal do Brasil aponta que um dos direitos e garantias fundamentais de qualquer cidadão é o "ir e vir" (BRASIL, 2006). Pautando-se nos preceitos de autonomia e segurança, de acordo com o Ministério das Cidades (BRASIL, 2008b), só é possível compreender o acesso de todos a qualquer ambiente através do próprio espaço urbano constituído pela cidade e de um sistema de transporte acessível.

Um serviço de transporte urbano que pode ser utilizado por todos confere à cidade a característica de ser um município preocupado com a acessibilidade do transporte coletivo por ônibus, diminuindo barreiras que restringem a participação e limitam atividades ou ocupações e minimizando situaçóes de desvantagem. Cidades acessíveis ampliam as oportunidades, colocando trabalho, saúde, lazer, escola, esporte e convivência ao alcance de todos. Não prover a infraestrutura e o serviço adequados é negar para uma parcela da população a oportunidade de usufruir da cidade (BRASIL, 2008b, p. 13).

Segundo Resende, Cavalcanti e Andrade (2012), a mobilidade na comunidade permite o envolvimento de indivíduos com algum tipo de deficiência em tarefas rotineiras. Isso apoia a manutenção do processo de desempenho da ocupaçáo dos indivíduos nos contextos em que eles se relacionam, possibilitando o desenvolvimento de atividade e participação, isto é, promovendo saúde e estados relacionados à saúde (ORGANIZAÇÃO..., 2003).

As pessoas com deficiência ou com mobilidade reduzida, os idosos, as mulheres grávidas e/ou os obesos são a diversidade populacional desses espaços (NERI, 2003). Dados do Censo Demográfico de 2010, do Instituto Brasileiro de Geografia e Estatística - IBGE, apontaram que 23,9\% da populaçáo brasileira declarou ter pelo menos uma das deficiências inquiridas, porcentagem que corresponde aproximadamente a 45,6 milhóes de pessoas. Dessas, em torno de 38,4 milhóes estão em áreas urbanas (INSTITUTO..., 2010) e, portanto, poderão em algum momento necessitar ou depender do serviço de transporte público para se deslocar e acessar os diversos serviços ofertados.

Para Torres (2006, p. 77),

[...] de nada adianta que sejam previstas rotas acessíveis sinalizadas e com dimensões recomendadas se os transportes coletivos não forem acessíveis.

O arcabouço jurídico brasileiro, que vem sendo estabelecido já há algum tempo com vistas a garantir o que é, por direito constitucional, instituído, busca reforçar os determinantes de acessibilidade e consequentemente sistematizar oportunidades de equiparação para todos (LIMA, 2007; BRASIL, 2004a, b).

Assim, compreendendo a importância da acessibilidade nos veículos de transporte coletivo, especificamente nos ônibus, para a manutenção e efetivação do envolvimento de diferentes pessoas que compóem uma dada sociedade, um mapeamento desse cenário no município, junto às pessoas que trabalham no veículo, forneceria dados iniciais acerca dessa temática. Desse modo, objetivou-se com este estudo descrever a acessibilidade do transporte coletivo urbano no município de Uberaba, MG, na perspectiva do motorista condutor e do cobrador.

\section{Procedimentos metodológicos}

Esta pesquisa é classificada pela sua natureza como quantitativa e constitui-se como estudo exploratório do tipo transversal descritivo (SAMPIERI; COLLADO; LUCIO, 2006), sendo realizada junto a motoristas e cobradores de uma das empresas de transporte coletivo de passageiros da cidade de Uberaba, MG.

Os critérios de inclusão dos sujeitos foram: ter função de motorista ou cobrador de ônibus de transporte coletivo em circulação na cidade pelo menos uma vez na semana; e declarar formalmente a participação, assinando o Termo de Consentimento Livre e Esclarecido. A pesquisa foi aprovada pelo Comitê de Ética da Universidade Federal do Triângulo Mineiro (Parecer nº 2385 de 2012).

Após o consentimento da sua direção, as entrevistas foram realizadas no estabelecimento da empresa, quando os motoristas e cobradores estavam iniciando o serviço, trocando o turno ou finalizando 
o expediente, de acordo com a disponibilidade de horário desses funcionários. Nenhuma entrevista aconteceu dentro de veículo.

A pesquisa ocorreu nos meses de outubro e novembro de 2012 e contou com uma amostra não probabilística (SAMPIERI; COLLADO; LUCIO, 2006; GIL, 2010).

Os dados foram coletados através de um formulário autoaplicável elaborado pelos pesquisadores que continha três questóes com respostas discursivas. Duas eram voltadas para a percepção dos motoristas e dos cobradores sobre a acessibilidade do veículo em que trabalham e a terceira era sobre a participação em capacitaçóes para uso desse(s) equipamento(s).

A análise das entrevistas foi feita pela análise de conteúdo temática proposta por Bardin (2010), resultando em três categorias temáticas, com subcategorias para a primeira e segunda questáo discursiva. Já na terceira questão foram identificadas somente categorias temáticas. Para todas as questóes, os resultados foram descritos em termos de frequência absoluta e relativa.

\section{Resultados e discussão}

Este estudo investigou uma amostra de motoristas e cobradores de ônibus com o objetivo de descrever, de acordo com a percepção deles, a acessibilidade do veículo de transporte público em que trabalhavam e com o qual circulavam pela cidade. No período de coleta de dados, 135 sujeitos foram convidados a participar desta pesquisa, sendo excluídos 23 motoristas e 12 cobradores por não aceitarem participar do estudo. Portanto, um total de 100 sujeitos constituiu a amostra deste estudo, os quais foram entrevistados no pátio de uma empresa de transporte coletivo de ônibus que opera na cidade de Uberaba, MG. O tempo médio para a aplicação do formulário de entrevista foi de dez minutos.

No que se refere à caracterização desses respondentes, quanto ao gênero, 20 eram do sexo feminino e 80 , do masculino; quanto à categoria funcional, 71 eram motoristas e 29, cobradores (Tabela 1).

Os resultados referentes à primeira questão discursiva derivaram nas categorias Acessibilidade

Tabela 1. Caracterização dos sujeitos $(\mathrm{n}=100)$.

\begin{tabular}{llc}
\hline \multicolumn{1}{c}{ Variável } & Subgrupo & n (\%) \\
\hline Sexo & Masculino & $80(80)$ \\
& Feminino & $20(20)$ \\
Categoria funcional & Motorista & $71(71)$ \\
& Cobrador & $29(29)$ \\
\hline
\end{tabular}

Fonte: questionários. adequada, Acessibilidade inadequada e Acessibilidade outros, que englobaram as percepçóes do motorista e do cobrador sobre a acessibilidade do ônibus em que trabalhavam. Os respondentes apontaram relevância de aspectos relacionados à condição da acessibilidade, à sua manutenção e às questóes vinculadas de acesso de usuários específicos ao veículo, bem como à área reservada para o uso da pessoa com cadeira de rodas (Tabela 2).

A categoria Acessibilidade inadequada foi referida pela maioria dos motoristas e cobradores (55\%). Necessidade de manutenção dos equipamentos existentes no veículo, tais como plataforma elevatória veicular, cinto de segurança para a pessoa na cadeira de rodas na área reservada e assento preferencia, foram os maiores problemas de acessibilidade percebidos pelos sujeitos. Especificamente, para cinco respondentes, a acessibilidade de determinados usuários, como idosos e obesos, apresenta maior dificuldade do que para outros.

Já na categoria Acessibilidade outros destacam-se apenas dois sujeitos, que fizeram referência a situaçóes em que foi necessário deixar um cadeirante no local de embarque por a área reservada a cadeirantes já estar ocupada por outros passageiros. Segunda a legislação vigente (ASSOCIAÇÃO..., 2006, p. 9), no interior do veículo, onde os passageiros se lotam, "deve haver uma área reservada para a acomodação de forma segura de pelo menos uma cadeira de rodas". Tais considerações apontam que mesmo o veículo estando adequado à norma de acessibilidade, no que se refere à quantidade de vagas reservadas para pessoas com cadeira de rodas o mesmo não consegue atender à demanda de deslocamento de pessoas cadeirantes de uma cidade de porte médio.

Por outro lado, na categoria Acessibilidade adequada, os motoristas e cobradores apontaram condiçôes de acessibilidade adequadas no veículo em que trabalhavam, sendo esta categoria o segundo apontamento mais identificado entre os entrevistados (35\%).

A segunda questão revelou as categorias Equipamento adequado, Equipamento inadequado e Equipamento outros, que englobaram a percepçáo dos motoristas e cobradores sobre a condiçáo dos equipamentos de acessibilidade do veículo em uso por eles. Os motoristas e cobradores referiram maior importância de aspectos como necessidade de manutenção do(s) equipamento(s), nível de qualidade e a necessidade de melhoria deles, além de apontarem questóes vinculadas à diferença entre veículos novos e antigos (Tabela 3).

A falta de manutenção dos equipamentos instalados no ônibus foi o item que os respondentes 
Tabela 2. Acessibilidade dos veículos $(\mathrm{n}=100)$.

\begin{tabular}{lrrr}
\hline \multicolumn{1}{c}{ Variável } & $\mathbf{n}(\%)$ & $\mathbf{n m}(\%)$ & $\mathbf{n c}(\%)$ \\
\hline Acessibilidade adequada & & & \\
$\quad$ Veículo acessível, sem irregularidades & $17(17)$ & $11(11)$ & $6(6)$ \\
Boa/normal & $18(18)$ & $12(12)$ & $6(6)$ \\
Total parcial & $35(35)$ & $23(23)$ & $12(12)$ \\
Acessibilidade inadequada & & & \\
Há necessidade de melhorias & $9(9)$ & $5(5)$ & $4(4)$ \\
Regular/médio & $6(6)$ & $6(6)$ & $0(0)$ \\
Ruim, não está preparado & $15(15)$ & $11(11)$ & $4(4)$ \\
Dificuldade de acesso de público específico & $5(5)$ & $2(2)$ & $3(3)$ \\
Necessidade de melhor manutenção & $20(20)$ & $14(14)$ & $6(6)$ \\
Total parcial & $55(55)$ & $38(38)$ & $17(17)$ \\
Acessibilidade outros & & & \\
Frota antiga $\times$ frota nova & $8(8)$ & $8(8)$ & $0(0)$ \\
Área especial destinada à cadeira de rodas & $2(2)$ & $2(2)$ & $0(0)$ \\
Total parcial & $10(10)$ & $10(10)$ & $0(0)$ \\
Total & $100(100)$ & $71(71)$ & $29(29)$ \\
\hline
\end{tabular}

Fonte: questionários. $\mathrm{n}$ = número total da amostra. $\mathrm{nm}$ = número sujeitos motoristas; $\mathrm{nc}=$ número sujeitos cobradores.

Tabela 3. Condição dos equipamentos disponíveis no veículo.

\begin{tabular}{lrrr}
\hline \multicolumn{1}{c}{ Variável } & $\mathbf{n}(\%)$ & $\mathbf{n m ~ ( \% )}$ & $\mathbf{n c}(\%)$ \\
\hline Equipamentos adequados & & & \\
$\quad$ Equipamentos ótimos & $4(4)$ & $2(2)$ & $2(2)$ \\
$\quad$ Equipamentos bons e de boa qualidade & $26(26)$ & $20(20)$ & $6(6)$ \\
$\quad$ Total parcial & $30(30)$ & $22(22)$ & $8(8)$ \\
Equipamentos inadequados & & & \\
$\quad$ Equipamentos que precisam melhorar & $17(17)$ & $12(12)$ & $5(5)$ \\
$\quad$ Ruim, equipamento de má qualidade & $8(8)$ & $3(3)$ & $5(5)$ \\
Necessidade de melhor manutenção & $32(32)$ & $21(21)$ & $11(11)$ \\
$\quad$ Total parcial & $57(57)$ & $36(36)$ & $21(21)$ \\
Equipamentos outros & & & \\
Frota antiga $\times$ frota nova & $9(9)$ & $9(9)$ & $0(0)$ \\
Beneficiam pessoas com necessidades especiais & $4(4)$ & $4(4)$ & $0(0)$ \\
$\quad$ Total parcial & $13(13)$ & $13(13)$ & $0(0)$ \\
Total & $100(100)$ & $71(71)$ & $29(29)$ \\
\hline
\end{tabular}

Fonte: questionários. $\mathrm{n}=$ número total da amostra; $\mathrm{nm}=$ amostra de sujeitos motoristas; $\mathrm{nc}=$ amostra de cobradores.

mais destacaram na categoria Equipamento inadequado. Em apontamentos que justificavam esse déficit de manutenção, ele foi atribuído à ausência de fiscalização pelos setores responsáveis. A Resolução no 84/98 do CONTRAN (Conselho Nacional de Trânsito) estabelecia normas para a inspeção dos veículos mas, no ano seguinte, a Resolução ${ }^{\circ}$ 107/99 suspendeu sua vigência (BRASIL, 2012) e, assim, a partir desse período alguns municípios têm estabelecido suas próprias determinações para a manutenção dos equipamentos de acessibilidade (SPTRANS, 2012).

De acordo com a ABNT NBR 14022/06 (ASSOCIAÇÃO..., 2006), os equipamentos de acessibilidade dos ônibus são: plataforma elevatória, rampa, área reservada (box) para cadeira de rodas e cão guia, dispositivos de segurança (cinto de segurança e sistema de travamento da cadeira de rodas, por exemplo) e dispositivos de sinalização, como a identidade visual do ônibus. Esses seriam os equipamentos que deveriam passar por manutenção preventiva recorrente.

Apesar do apontamento sobre a necessidade de manutenção dos ônibus, a maioria dos entrevistados indicou que as condiçóes desses equipamentos eram boas e de qualidade, constituindo o segundo indicativo dado pelos motoristas e cobradores: Equipamento adequado. Consideraçóes a respeito 
Tabela 4. Capacitação para uso dos equipamentos de acessibilidade.

\begin{tabular}{lrrr}
\hline \multicolumn{1}{c}{ Variáveis } & n (\%) & nm (\%) & nc (\%) \\
\hline Com treinamento & & & \\
$\quad$ Realizado pela empresa & $97(97)$ & $68(68)$ & $29(29)$ \\
Realizado em outros locais & $2(2)$ & $2(2)$ & $0(0)$ \\
$\quad$ Deficitário & $1(1)$ & $1(1)$ & $0(0)$ \\
Sem treinamento & $0(0)$ & $0(0)$ & $0(0)$ \\
Total & $100(100)$ & $71(71)$ & $29(29)$ \\
\hline
\end{tabular}

Fonte: questionários. $\mathrm{n}=$ número total da amostra; $\mathrm{nm}=$ amostra de sujeitos motoristas; $\mathrm{nc}=$ amostra de cobradores .

desses resultados merecem uma observaçáo mais contextualizada na medida em que no período da pesquisa a empresa de transporte urbano estava em auditoria interna, para avaliação do serviço prestado por ela. Assim, questóes referentes a esse dado podem ser discutidas em outras pesquisas, avaliando-se a real condição dos veículos de transporte coletivo de forma a verificar a qualidade dos equipamentos em uso.

$\mathrm{Na}$ categoria Equipamentos outros, nove sujeitos apontam diferenças entre os equipamentos da frota de veículos novos e os dos antigos e quatro relataram que essas diferenças são para benefício das pessoas com deficiência. De acordo com a Lei no $10.048 / 00$, em seu terceiro artigo, pessoas com deficiência, idosos, gestantes, lactantes acompanhadas por criança de colo têm direito a assentos reservados com a devida identificação nos veículos de transporte coletivo. $\mathrm{Na}$ mesma perspectiva, essa lei estabelece normas gerais e critérios para a promoçáo da acessibilidade e institui a acessibilidade nos veículos de transporte coletivo, reportando o cumprimento dos requisitos estabelecidos nas normas técnicas vigentes, a saber, a ABNT NBR 9050/04 (ASSOCIAÇÃO..., 2004) e a ABNT NBR 14022/06 (ASSOCIAÇÃO..., 2006).

O Decreto 5.296/04 também sustenta o arcabouço jurídico que fundamenta a visão dos entrevistados com relação à importância da acessibilidade para o direito de se deslocar em veículos de transporte coletivo das pessoas (BRASIL, 2004c).

Com relação à terceira pergunta, referente à capacitação dos motoristas e cobradores para uso do(s) equipamento(s), apurou-se se o funcionário tinha recebido treinamento para usar os equipamentos destinados à acessibilidade disponíveis no veículo e quem havia fornecido esse treinamento (Tabela 4). Todos os entrevistados responderam que foram treinados para usar os equipamentos de acessibilidade do veículo, no entanto uma minoria (1\%) apontou que a capacitação foi deficitária, descrevendo situações nas quais não sabiam efetivamente como manusear dispositivos como, por exemplo, a plataforma ou a rampa.

\section{Considerações finais}

Este estudo possibilitou a descrição da acessibilidade do transporte coletivo urbano no município de Uberaba, MG, na perspectiva do motorista condutor e do cobrador. Os resultados apontam que a frota de ônibus coletivos em circulação na cidade, na empresa pesquisada, de acordo com as consideraçóes dos respondentes, apresenta equipamentos inadequados, o que repercute em uma acessibilidade restrita devido a diversos fatores, como falta de manutenção preventiva e periódica, dificuldade de acesso por parte de usuários específicos e falta de instalação dos dispositivos de acessibilidade nos veículos, dentre outros.

No que diz respeito à capacitação da categoria profissional, percebeu-se que, apesar de todos os sujeitos terem sido preparados para a utilizaçáo dos equipamentos de acessibilidade do veículo, manifestou-se a necessidade de novos treinamentos buscando sensibilizar esses profissionais para o uso dos equipamentos, bem como buscando ampliar a compreensão deles em relação ao conteúdo da acessibilidade. Identificar a real habilidade de manuseio dos dispositivos pelos trabalhadores do transporte e uma maior atenção dirigida à população considerada como portadora de necessidades especiais são pertinentes para a equidade e efetividade do serviço prestado.

Apesar de a temática ser uma discussáo mundial e existir vasta literatura na legislação brasileira que normatiza e determina diretrizes sobre acessibilidade, a produçáo científica nacional existente é significativamente limitada. Acredita-se que implementar pesquisas de campo que investiguem as lacunas não cobertas pelas diretrizes e normas e que analisem a perspectiva da acessibilidade também do ponto de vista dos usuários poderá constituir avanços para a melhoria contínua do serviço prestado à população e para a manutenção do direito de "ir e vir" instituído pela Constituição Federal.

Nesse sentido, novas pesquisas devem ser realizadas a fim de avaliar a aplicabilidade e o cumprimento 
das normas e diretrizes voltadas para a acessibilidade dos transportes coletivos nas cidades, de forma a subsidiar discussóes mais aprofundadas e fornecer embasamento teórico-prático acerca das dificuldades cotidianas vivenciadas por usuários e profissionais do transporte coletivo (motoristas e cobradores).

\section{Referências}

ASSOCIAÇÃO BRASILEIRA DE NORMAS TÉCNICAS - ABNT. NBR 9050: Acessibilidade a edificações, mobiliário, espaços e equipamentos urbanos. Rio de Janeiro: ABNT, 2004.

ASSOCIAÇÃO BRASILEIRA DE NORMAS TÉCNICAS - ABNT. NBR 14022: Acessibilidade em veículos de características urbanas para o transporte coletivo de passageiros. Rio de Janeiro: ABNT, 2006.

BARDIN, L. Análise de Conteúdo. Lisboa: Edições70, 2010. BRASIL. Constituição (1988). Constituição da República Federativa do Brasil: Texto promulgado em 5 de outubro de 1988, com as alteraçôes adotadas pelas Emendas Constitucionais no $1 / 92$ a 52/2006 e pelas Emendas Constitucionais de Revisão no 1 a 6/94. Brasília: Senado Federal, Subsecretaria de Edições Técnicas, 2006.

BRASIL. Presidência da República. Lei no 10.048 de 08 de novembro de 2000. Dá prioridade de atendimento às pessoas que especifica, e dá outras providências. Diário Oficial da República Federativa do Brasil, Brasília, DF, 09 nov. 2004a. Seção 1. Disponível em: <http://www. planalto.gov.br/ccivil_03/leis/L10048.htm>. Acesso em: 03 nov. 2012.

BRASIL. Presidência da República. Lei no 10.098 de 08 de novembro de 2000. Estabelece normas gerais e critérios básicos para apromoção da acessibilidade das pessoas portadoras de deficiência ou com mobilidade reduzida, e dá outras providências. Diário Oficial da República Federativa do Brasil, Brasilia, DF, 09 nov. 2004b. Seção 1. Disponível em: <http://www.planalto.gov.br/ccivil_03/ leis/L10098.htm>. Acesso em: 03 nov. 2012.

BRASIL. Presidência da República. Decreto no 5.296 de 02 de dezembro de 2004. Regulamenta as Leis $\mathrm{n}^{\circ} 10.048$, de 8 de novembro de 2000 , que dá prioridade de atendimento às pessoas que especifica, e $\mathrm{n}^{\circ} 10.098$, de 19 de dezembro de 2000, que estabelece normas gerais e critérios básicos para a promoção da acessibilidade das pessoas portadoras de deficiência ou com mobilidade reduzida, e dá outras providências. Diário Oficial da
República Federativa do Brasil, Brasília, DF, 03 dez. 2004c. Seção 1. Disponível em: <http://www.planalto.gov.br/ ccivil_03/_ato2004-2006/2004/decreto/d5296.htm>. Acesso em: 03 nov. 2012.

BRASIL. Código de Trânsito Brasileiro CTB. Código de trânsito brasileiro e legislação complementar em vigor. 1. ed. Brasília: Denatran, 2008a.

BRASIL. Ministério das Cidades. Brasil Acessível - Programa brasileiro de acessibilidade urbana. Implantação de sistemas de transporte acessiveis - 5. 2. ed. Brasília: Secretaria Nacional de Transporte e da Mobilidade Urbana, 2008b.

BRASIL. Ministério das Cidades. Departamento Nacional de Trânsito - DENATRAN. Conselho Nacional de Trânsito. Disponível em: <http://www.denatran.gov.br/>. Acesso em: 20 nov. 2012.

GIL, A. C. Como elaborar projetos de pesquisa. 5. ed. São Paulo: Atlas, 2010.

INSTITUTO BRASILEIRO DE GEOGRAFIA E ESTATÍSTICA - IBGE. Censo demográfico 2010: Características gerais da população, religião e pessoas com deficiência. Rio de Janeiro: IBGE, 2010.

LIMA, N. M. Pessoa Portadora de Deficiência: Legislação Federal Básica. Brasília: SEDH, Coordenadoria Nacional para Integraçáo da Pessoa Portadora de Deficiência, 2007.

NERI, M. Retratos da deficiência no Brasil. Rio de Janeiro: FGV/IBRE, CPS, 2003.

ORGANIZAÇÃO MUNDIAL DE SAÚDE - OMS. Classificação Internacional de Funcionalidade, Incapacidade e Saúde - CIF. São Paulo: EdUSP, 2003.

RESENDE, M. G. A.; CAVALCANTI, A.; ANDRADE, V. S. Veículo adaptado: caracterização de suas adaptaçóes e do perfil de seus condutores. Cadernos de Terapia Ocupacional da UFSCar, São Carlos, v. 20, n. 1, p. 73-80, 2012. http://dx.doi.org/10.4322/cto.2012.008

SAMPIERI, R. H.; COLLADO, C. F.; LUCIO, P. B. Metodologia de Pesquisa. 3. ed. São Paulo: McGraw Hill, 2006.

SPTRANS. Inspeção veicular do sistema municipal de transportes. São Paulo: SPTrans, 2012. Disponível em: <http://www.sptrans.com.br/pdf/ biblioteca_tecnica/INSPECAO_VEICULAR_DO_ SISTEMA_MUNICIPAL_DE_TRANSPORTES.pdf $>$. Acesso em: 17 out. 2012.

TORRES, F. P. T. Guia de acessibilidade urbana. Belo Horizonte: Prefeitura Municipal de Belo Horizonte, 2006.

\section{Contribuição dos Autores}

Alessandra Cavalcanti elaborou o projeto de pesquisa, orientou a coleta de dados, analisou os dados e redigiu o texto. Alysson Lourenço Alves analisou os dados e redigiu o texto. Ana Flávia Rodrigues Vieira elaborou o projeto de pesquisa e coletou os dados. Alberto Koston Aramaki coletou dados. Ana Paula Santos Santana coletou dados.

\section{Notas}

${ }^{1}$ Este artigo é parte integrante do projeto de pesquisa Acessibilidade em transporte público na cidade de Uberaba - MG, aprovado pelo Comitê de Ética em Pesquisa em Seres Humanos da UFTM de acordo com o Parecer no 2385/2012. 